\title{
Polycystic Ovary Syndrome is Affected and Protected by $D D$ and DI Genotypes of Angiotensin Converting Enzyme, Respectively: An Update of a Meta-Analysis
}

\author{
Fatemeh Yari ${ }^{1}$, Kamran Aeinfar ${ }^{2}$, Saber Abbaszadeh $^{3}$, Khatereh Anbari $^{4}$, Seyyed Amir Yasin Ahmadi ${ }^{3 *}$
}

\begin{abstract}
Objectives: Angiotensin converting enzyme (ACE) is an important enzyme involved in the physiopathology of renal, cardiovascular and ovarian systems. One of these ACE related diseases is polycystic ovary syndrome (PCOS).

Materials and Methods: We intend to update the only meta-analysis written by Jia et al in 2013 on the association of ACE gene polymorphism and risk of PCOS. The reason of our attempt to update this meta-analysis was that they found no significant relation in their meta-analysis. For this aim, we searched in databases for relevant documents.

Results: We found 8 relevant papers, 6 of which had been covered by Jia et al meta-analysis. In order to perform this meta-analysis, we used comprehensive meta-analysis software. The analysis was done through $P$ value and sample size of each study based on fixed-effect model. Analyses were performed in 5 different groups of alleles and genotypes. Among these 5 analyses, 4 of them were statistically significant. Hereby, we concluded that $D D$ genotype of $A C E$ is a risk factor for PCOS $(P$ value $=0.013$; odds ratio $[\mathrm{OR}]=$ $1.195)$, while $D I$ is the protecting genotype $(P=0.009$; $\mathrm{OR}=0.819)$.

Conclusion: Hence, it is suggested to use a very low dose of captopril as an ACE inhibitor in the PCOS patients having DD genotype in future as a clinical trial, just as a scientific model. Further investigation on ovary ACE system is needed.

Keywords: Angiotensin converting enzyme inhibitors, Meta-analysis, Polycystic ovary syndrome
\end{abstract}

\section{Introduction}

Angiotensin converting enzyme (ACE) is a renal enzyme catalyzing the conversion of angiotensin 1 to angiotensin 2. This, results in production of the aldosterone resulting in natrium retention and potassium excretion. ACE gene has 3 polymorphic genotypes of $I I, D I$ and $D D$. It has been observed in several studies and meta-analyses that patients with $D D$ genotype are more at risk of renal and cardiovascular diseases. It seems that these effects could be due to hyperactivity of $A C E$ gene in such patients $(1,2)$. In addition to kidneys, ovaries have renin angiotensin system (RAS). The role of this system in ovulation and reproduction is not completely understood (3).

Different histopathologic and angiogenic abnormal conditions result in pregnancy complications (4). Polycystic ovary syndrome (PCOS) is one of such conditions resulting in infertility and other complications of women's reproductive system (5). Based on a metaanalysis conducted by Jalilian et al, prevalence of PCOS in Iran was $6.8 \%, 4.41 \%$ and $19.5 \%$ based on $\mathrm{NIH}$, ultrasound and Rotterdam criteria, respectively (6). Type 2 diabetes, obesity, metabolic syndrome, hypertension and so on are considered as risk factors of PCOS (7-9). Also metformin is used for the treatment, because of insulin resistance in such patients (10). All of these evidences give us clues that hypertension related genes like $A C E$ my play roles in pathogenesis of PCOS. Of course it is not clear whether this role is associated with renal RAS, ovarian RAS or both.

On the occasion of the clues and findings above, we intend to update the only meta-analysis conducted by Jia et al in 2013 on the association of ACE gene polymorphism and risk of PCOS (11). The reason of our attempt to update this meta-analysis was that Jia et al did not find any significant relation in their random-effect model meta-analysis.

\section{Materials and Methods}

We searched in databases for relevant keywords in the titles of the articles (Figure 1). Finally we found 8 relevant papers based on our inclusion criteria (similar protocols including similar criteria for their PCOS and control groups). In order to perform this meta-analysis, we used comprehensive meta-analysis version 2 software (Biostat, US). The analysis was done through the $\mathrm{P}$ value and sample size of each study using fixed-effect model. Analyses were performed in 5 different groups of allele and genotype comparisons (Table 1). This meta-analysis 


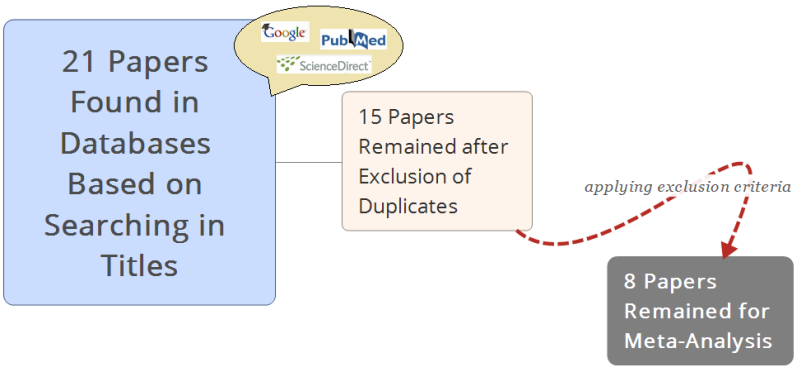

Figure 1. Searching Algorithm of Relevant Articles.

covers information of totally 3046 individuals of both PCOS and control groups. Since the $P$ values had been calculated with Yate correction (or Fisher exact test if necessary), the odds ratios (ORs) achieved from these $P$ values are under-estimated.

In order to recognize publication bias, we used funnel plots (12). Being in the funnel for each study was considered as homogeneity. In cases of heterogeneity, we corrected manually the weights of the heterogenic studies instead of using random-effect model. This correction (weight decreasing) was through increasing the standard error of having bias studies. In such cases we used the effect size instruction "log OR and standard error" instead of " $P$ value and sample size." Of course the mentioned ORs are achieved from the P values; because conventional calculation of OR, makes the effect sizes over-estimated in comparison to using $\mathrm{P}$ values with Yate's correction. For multiple comparisons of the results of the mentioned 5 groups, Benjamini-Hochberg correction was used.

\section{Results}

Among the 8 studies imported in the meta-analysis, 6 of them had been covered by Jia et al meta-analysis (13-18). Analyses were performed in 5 different groups of alleles and genotypes including $D$ vs $I$ (Figures 2,3 ), $D D$ vs $I I$ (Figures 4,5 ), $D D+D I$ vs $I I$ (Figures 6,7 ), $D D$ vs $D I+I I$ (Figures 8,9 ), and $D I$ vs $D D+I I$ (Figures 10, 11). Among these 5 analyses, 4 of them were statistically significant (Table 1). After applying the multiple comparison correction, they still remained significant. The publication bias and their weight corrections are pointed out in the funnel plots (Figures 2A, 4A, 4B, 6A, 6B, 8A, 8B, 10A, and $10 \mathrm{~B})$. The meta-analysis results are shown in the forest plots (Figures 2B, 4C, 6C, 8C and 10C). Impact of ethnicities and sample sizes on the results are shown as meta-regressions (Figures 3, 5, 7, 9 and 11).

As we said, the previous meta-analysis found no significant correlation between ACE genotypes and PCOS. This could be due to their smaller size of total population and using random-effect model. As we checked in our funnel plots, using the random-effect model was not able to correct the heterogeneities of the studies. Therefore, we used fixed-effect model instead, and in order to correct the heterogeneities we decreased the weights of the studies having publication bias. Our statistical aim for this homogenizing was to move the co-ordination of such studies from outside to inside of the funnel in funnel plots.

For the analysis $D$ vs $I$, firstly we found a significant correlation (Table 1), but after applying the needed weight correction (Figure 1A), this significance correlation did not remain (Table 1). Its justification could be the protecting

Table 1. Data Summery and $P$ values of the Imported Studies

\begin{tabular}{|c|c|c|c|c|c|c|}
\hline Study & Population (Ethnicity) & $D$ vs $I$ & $D D$ vs II & $D D+D /$ vs II & $D D$ vs $D I+I I$ & $D I$ vs $D D+I I$ \\
\hline Sun et al (13) & 249 (Asian) & $0.4884(-)$ & $0.2654(-)$ & $0.3994(+)$ & $0.3078(-)$ & $0.8875(+)$ \\
\hline Sun et al (16) & 582 (Asian) & $0.3482(+)$ & $0.1167(+)$ & $0.2222(+)$ & $0.1703(+)$ & $0.9203(-)$ \\
\hline Karabulut et al (15) & 63 (Caucasian) & $0.4463(-)$ & $1(+)$ & $1(-)$ & $0.2418(+)$ & $0.1809(-)$ \\
\hline Celik et al (14) & 63 (Caucasian) & $0.3994(+)$ & $0.4054(+)$ & $1(+)$ & $0.0457(+) *$ & $0.0584(-)$ \\
\hline Bayram et al (17) & 200 (Caucasian) & $0.0344(+) *$ & $0.0239(+) *$ & $0.4976(+)$ & $0.0001(+) *$ & $0.0011(-)^{*}$ \\
\hline Koika et al (18) & 1067 (Caucasian) & $0.8414(+)$ & $0.1502(+)$ & $0.0333(+) *$ & $0.6315(-)$ & $0.0488(+) *$ \\
\hline Deepika et al (19) & 574 (Indian) & $0.8230(+)$ & $0.8414(-)$ & $0.0864(-)$ & $0.0609(+)$ & $0.0010(-) *$ \\
\hline Ożegowska et al (20) & 248 (Caucasian) & $0.0002(+) *$ & $0.0001(+) *$ & $0.0001(+) *$ & $0.0001(+) *$ & $0.3348(-)$ \\
\hline \multirow{2}{*}{ Meta-analysis } & $\begin{array}{l}P \text { value before } \\
\text { homogenizing }\end{array}$ & $0.046(+) *$ & $0.004(+) *$ & $0.011(+) *$ & $0.001 *(+)$ & $0.077(-)$ \\
\hline & $\begin{array}{l}P \text { value after } \\
\text { homogenizing }\end{array}$ & $0.171(+)$ & $\begin{array}{l}0.022(+) * \\
\text { OR }=1.169\end{array}$ & $\begin{array}{l}0.013(+) * \\
O R=1.195\end{array}$ & $\begin{array}{l}0.033(+) * \\
O R=1.160\end{array}$ & $\begin{array}{l}0.009(-) * * \\
\text { OR }=0.816\end{array}$ \\
\hline Multiple comparison & Corrected $P$ value & $0.171(+)$ & $0.036(+) *$ & $0.032(+) *$ & $0.041(+) *$ & $0.045(-) *$ \\
\hline \multirow{2}{*}{ Homogenizing } & Corrected-weight study & Ożegowska & Ożegowska & $\begin{array}{l}\text { Ożegowska and } \\
\text { Deepika }\end{array}$ & $\begin{array}{l}\text { Ożegowska and } \\
\text { Bayram }\end{array}$ & $\begin{array}{l}\text { Koika and } \\
\text { Bayram }\end{array}$ \\
\hline & $\begin{array}{l}\text { Previous/corrected } \\
\text { standard error }\end{array}$ & $0.239 / 0.4$ & $0.239 / 0.37$ & $\begin{array}{l}0.239 / 0.37 \\
0.152 / 0.22\end{array}$ & $\begin{array}{l}0.239 / 0.38 \\
0.269 / 0.44\end{array}$ & $\begin{array}{l}0.111 / 0.20 \\
0.269 / 0.35\end{array}$ \\
\hline
\end{tabular}

Abbreviation: OR, odds ratio.

Note: (+) shows risk factor and (-) shows protecting factor.

* Significance level is at 0.05 . 

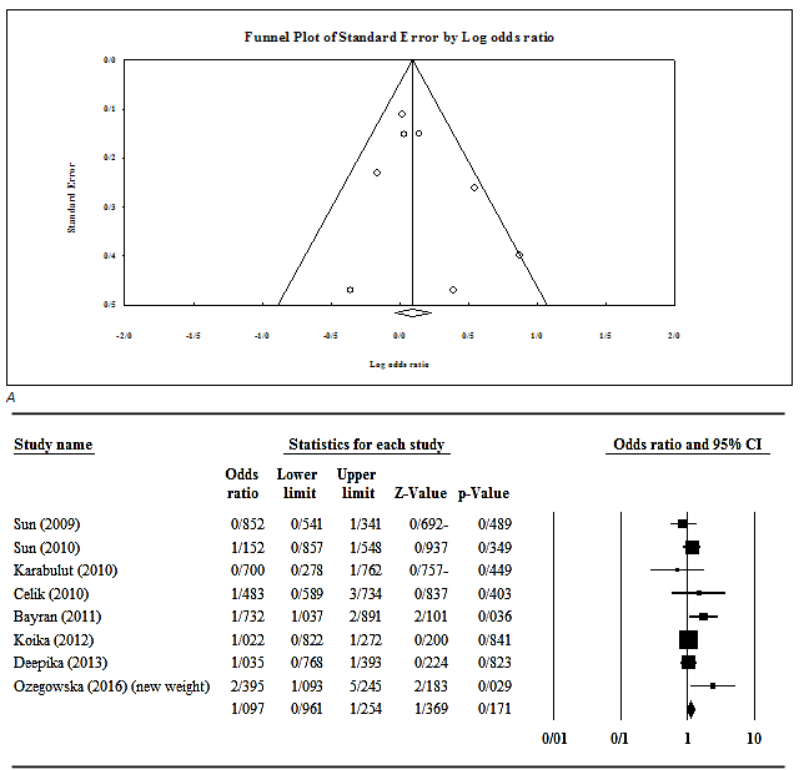

Figure 2. (A) Funnel plot for $D$ vs I after homogenizing. (B) Forest plot for $D$ vs $I$.
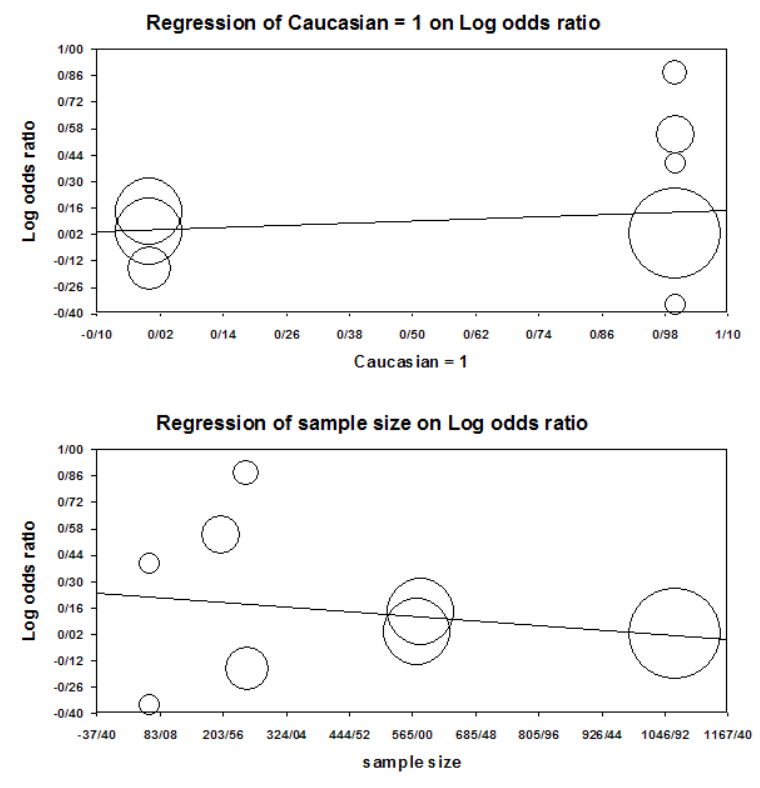

Figure 3. (A) Meta-regression of $D$ vs / for ethnicities of the studied populations. (B) Meta-regression of $D$ vs I for sample size of the studied populations.

effect of $D I$ genotype in spite of the negative effect of $D D$ genotype on PCOS. For the analysis $D D$ vs $I I$, after weight correction (Figure $4 \mathrm{~B}$ ), the risk factor role of $D D$ genotype, remained significant (Table 1). Similarly, for the analysis $D D+D I$ vs $I I$, after weight correction (Figure $6 \mathrm{~B}$ ), the risk factor role of $D D$ genotype remained significant (Table 1). Its justification could be the protecting effect of II genotype in spite of the protecting effect of DI genotype on PCOS. For the analysis $D D$ vs $D I+I I$, after weight correction (Figure $8 \mathrm{~B}$ ), the risk factor role of $D D$ genotype remained
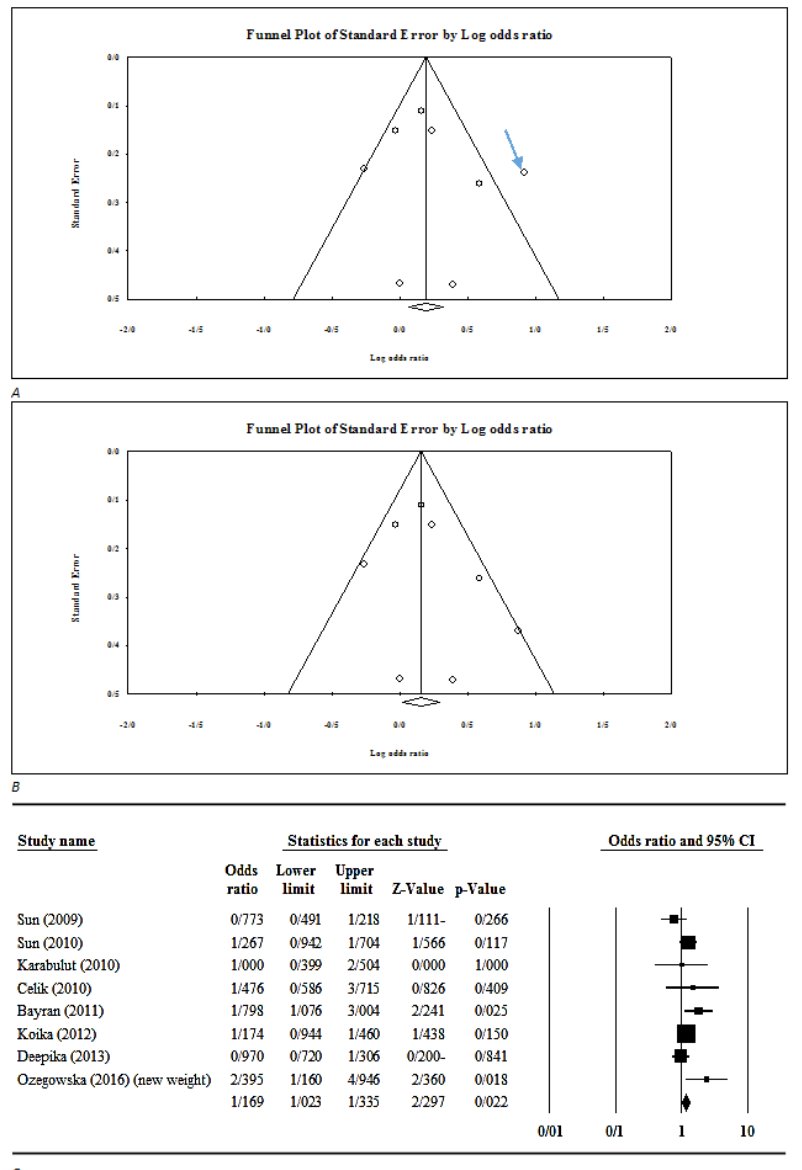

Figure 4. (A) Funnel plot for $D D$ vs II. One publication bias has been found. B) Funnel plot for DD vs II after homogenizing. (C) Forest plot for $D D$ vs $/ /\left({ }^{*} P=0.022\right)$.
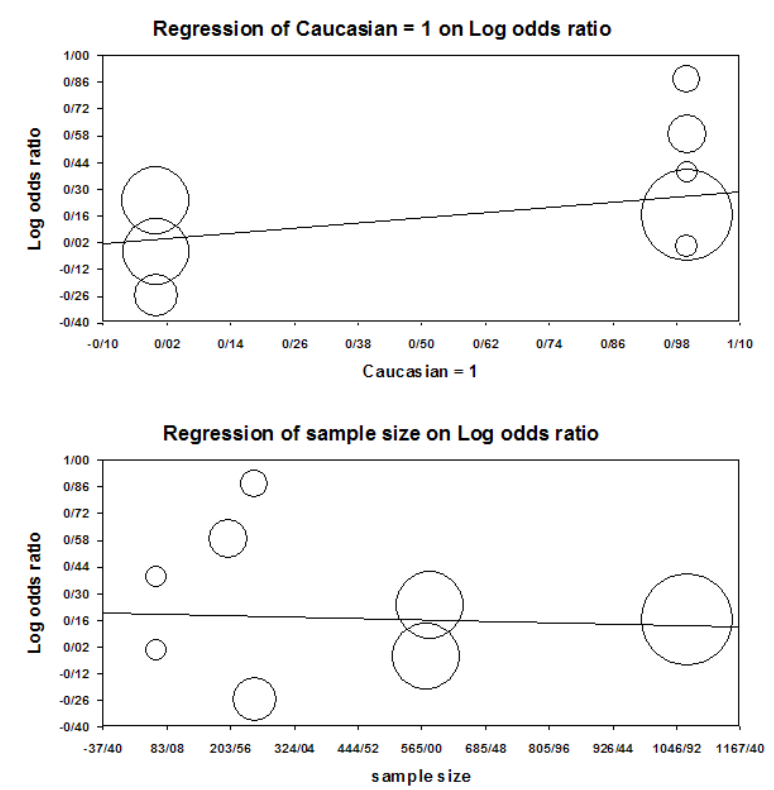

Figure 5. (A) Meta-regression of $D D$ vs // for ethnicities of the studied populations. (B) Meta-regression of $D D$ vs // for sample size of the studied populations. 

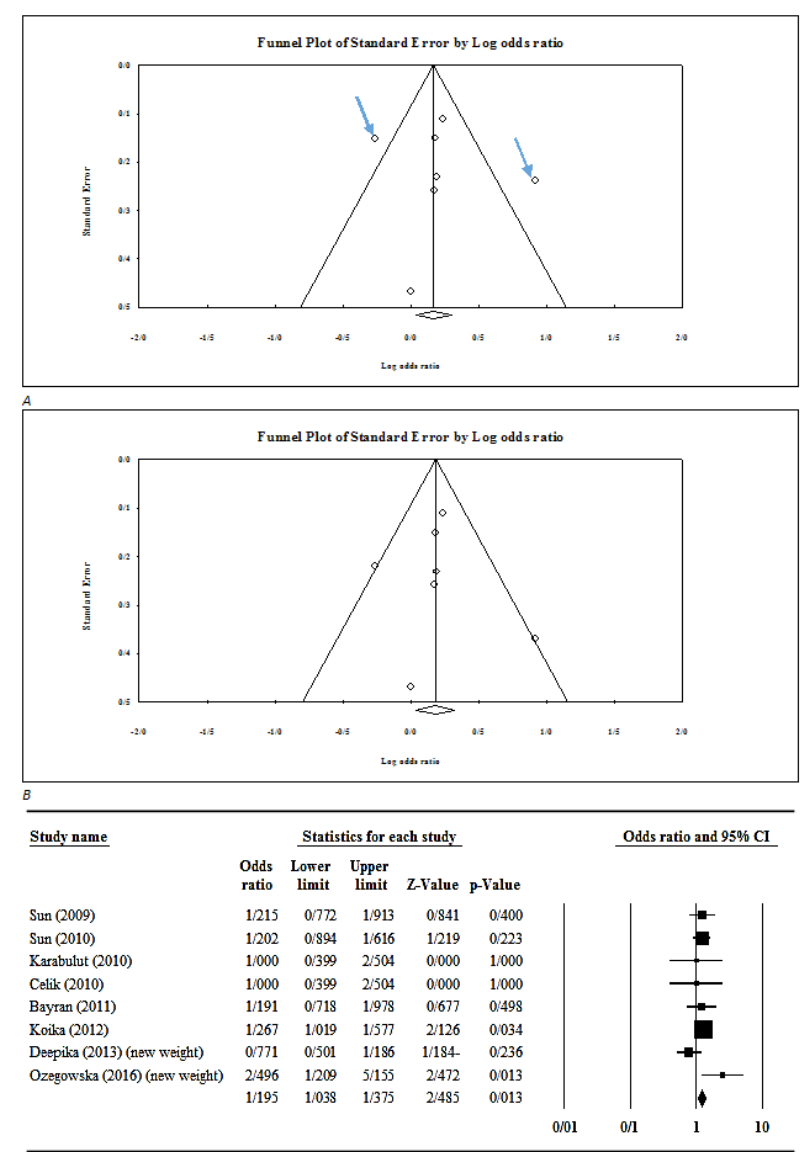

Figure 6. (A) Funnel plot for $D D+D /$ vs II. Two publication bias analyses have been found. (B) Funnel plot for $D D+D I$ vs II after homogenizing. (C) Forest plot for $D D+D /$ vs $I I$. ( $\left.{ }^{*} P=0.013\right)$
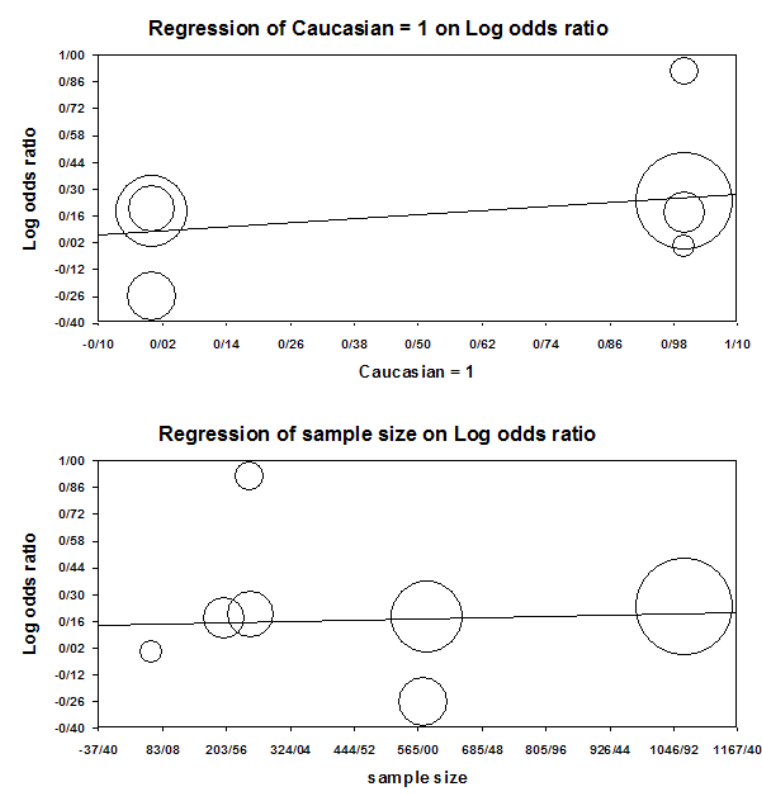

Figure 7. (A) Funnel plot for $D D+D /$ vs II. Two publication bias analyses have been found. (B) Funnel plot for DD+DI vs II after homogenizing. (C) Forest plot for $D D+D /$ vs $I I .\left({ }^{*} P=0.013\right)$
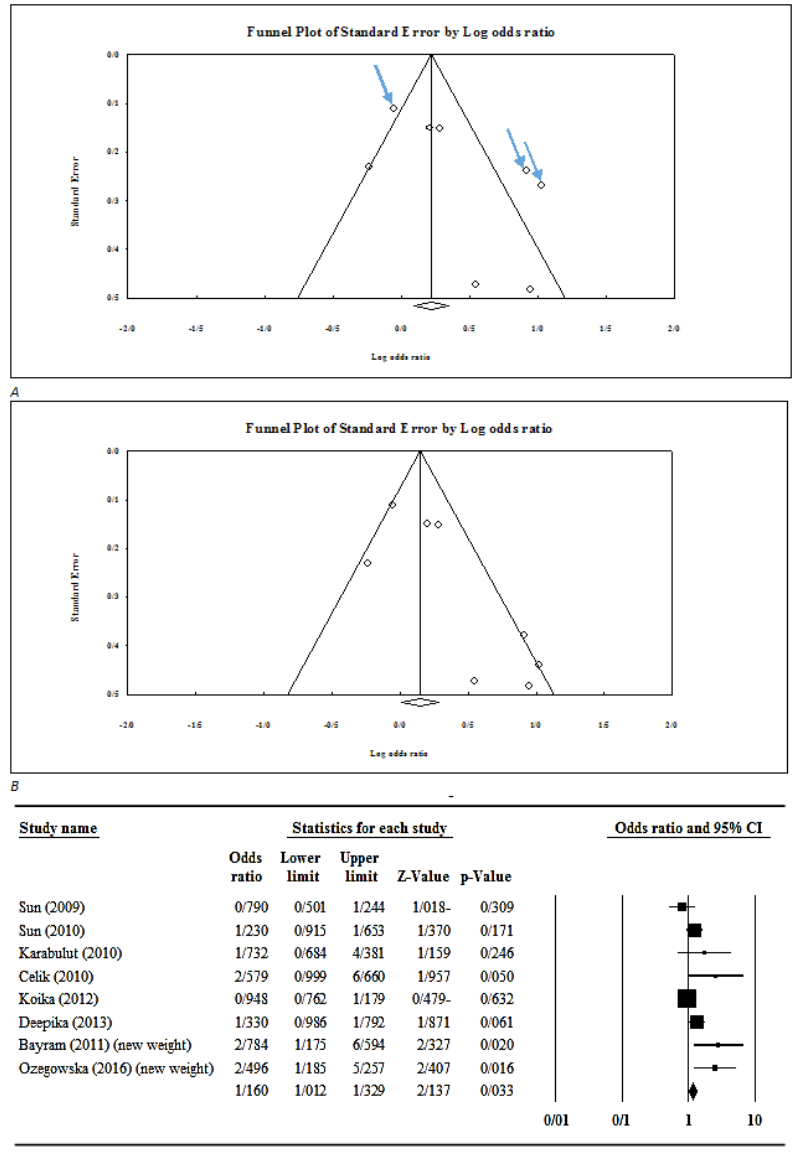

Figure 8. (A) Funnel plot for DD vs DI+II. Three publication bias have been found. Weight correction on 2 of them should be performed. (B) Funnel plot for $D D$ vs $D I+l l$ after homogenizing. (C) Forest plot for $D D$ vs $D /+/ I\left({ }^{*} P=0.033\right)$

significant (Table 1). For the analysis $D I$ vs $D D+I I$, after weight correction (Figure 10B), the protecting role of $D I$ genotype remained significant (Table 1).

The meta-regressions show that these roles of $A C E$ polymorphism in PCOS are not affected by Caucasian race (Figures 3A, 5A, 7A, 9A and 11A). In meta-regressions of the study sample sizes, it is observed that the risk factor role of $D D$ genotype decreases in larger populations (Figure 9B), and also the protecting role of DI genotype decreases in larger populations (Figure 11B). Of course these plots are based on our weight-corrected model.

\section{Discussion}

Role of genetic polymorphisms in pathogenesis of PCOS has been previously described. For instance, Panda et al have shown in a systematic review that up to now 43 different types of proteins are involved in pathogenesis of PCOS (ACE protein was not among them). Most of them were insulin related genes and proteins (21). The exact molecular pathogenesis of PCOS is still unclear. Infertility is one of the complications of PCOS (4). In such patients, controlled ovarian stimulation could be used (22), although ovarian hyper-stimulation has its own problems $(23,24)$. For this reason, spontaneous abortion is higher 

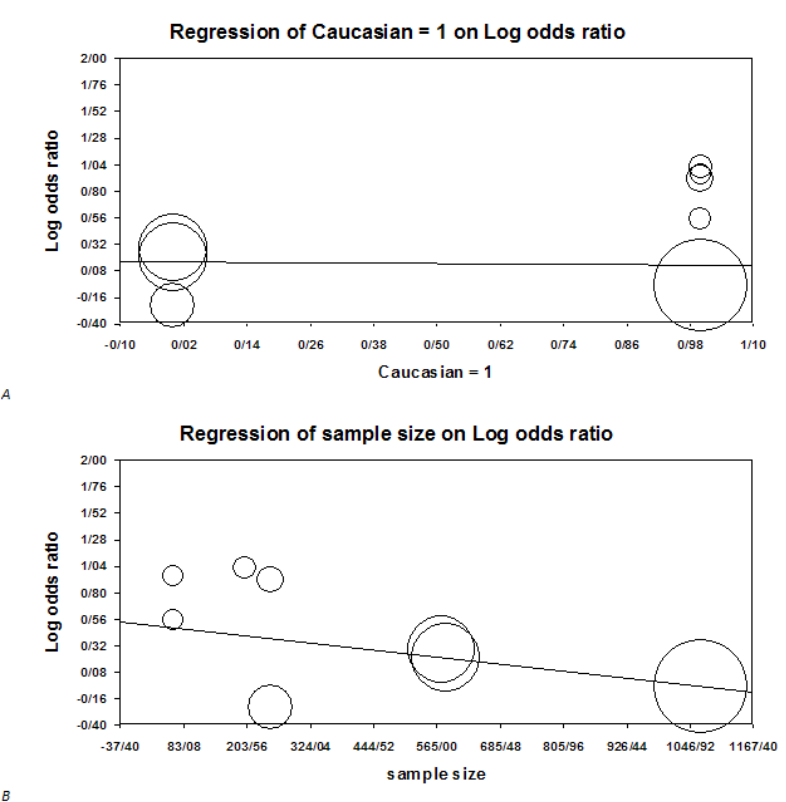

Figure 9. (A) Meta-regression of $D D$ vs $D /+/ /$ for ethnicities of the studied populations. B) Meta-regression of $D D$ vs $D /+/ /$ for sample size of the studied populations ( ${ }^{*}$ Slope $P=0.012$ )

in PCOS patients even after using assisted reproductive technologies (4).

As described by Cheng et al, paternal history of diabetes mellitus and hypertension can increase the risk of PCOS (25). Another study believes that familial history of obesity, diabetes mellitus and hypertension increase the risk of PCOS (26). Since familial hypertension seems to be an angiotensin related phenotype (27), ACE gene polymorphism might be effective in the incidence and severity of PCOS. Of course this estimation is based on the renal RAS.

It seems and is hypothesized that both renal and ovarian RAS might be involved in physiopathology of PCOS. Ovarian RAS is involved in ovulation process whereas renal RAS is involved in blood pressure and hemodynamic changes. The role of hyper- and hypo-activity of RAS may be paradoxically different. Biochemistry wise, aldosterone as the outcome of RAS, is a part of cholesterol related cycles of metabolism. Hence the hyperlipidemia, insulin resistance and hyperandrogenism occurred in PCOS will not be unfamiliar to renal RAS. Therefor statins (28) and spironolactone (29) can be used for treatment of PCOS because they directly and indirectly related to the abovementioned mechanisms.

\section{Conclusion}

It is concluded that the hypertension related gene ACE is associated with PCOS. Although this association is statistically significant, the ORs are not distant enough from one to show a highly effective role. Since the physiological activity of $D I$ genotype is between $D D$ and $I I$, it seems that both hyper- and hypo-activity of ACE gene could be harmful for PCOS (but more of hyperactivity) as a scientific model. Hence it is suggested to use
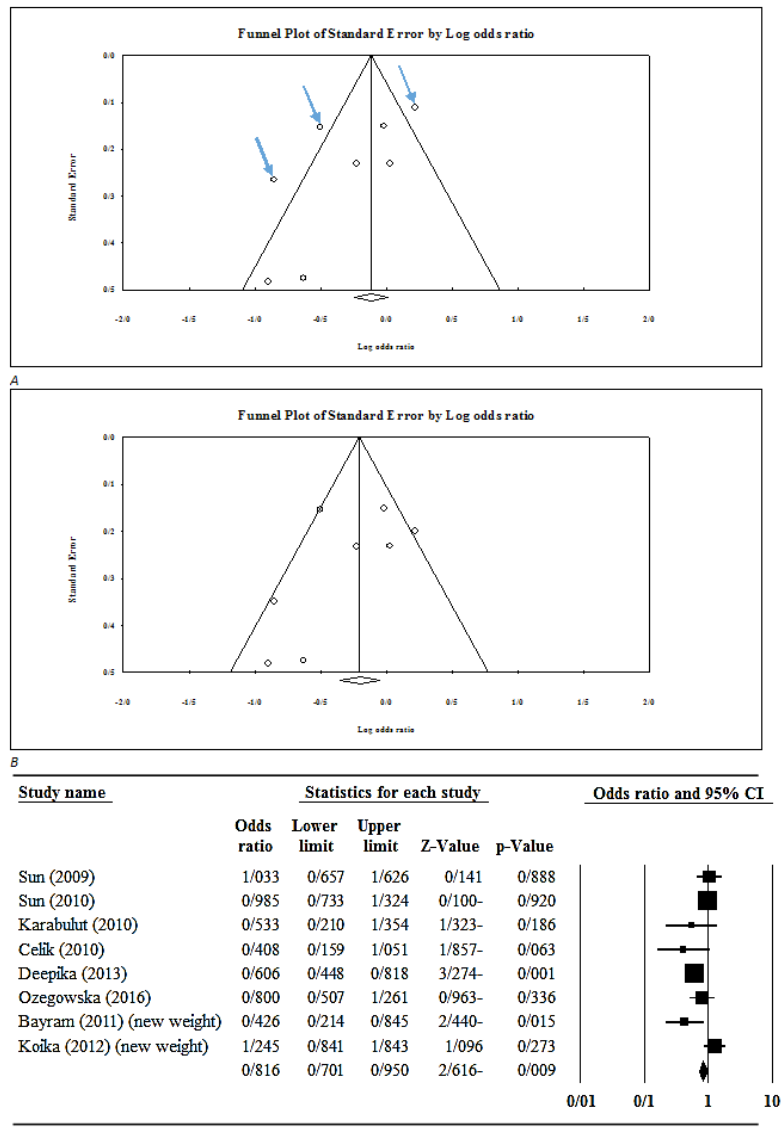

Figure 10. (A) Funnel plot for DI vs DD+II. Three publication bias analyses have been found. Weight correction on two of them should be performed. B) Funnel plot for $D I$ vs $D D+/ /$ after homogenizing. (C) Forest plot for $D /$ vs $D D+I /\left({ }^{* *} P=0.009\right)$
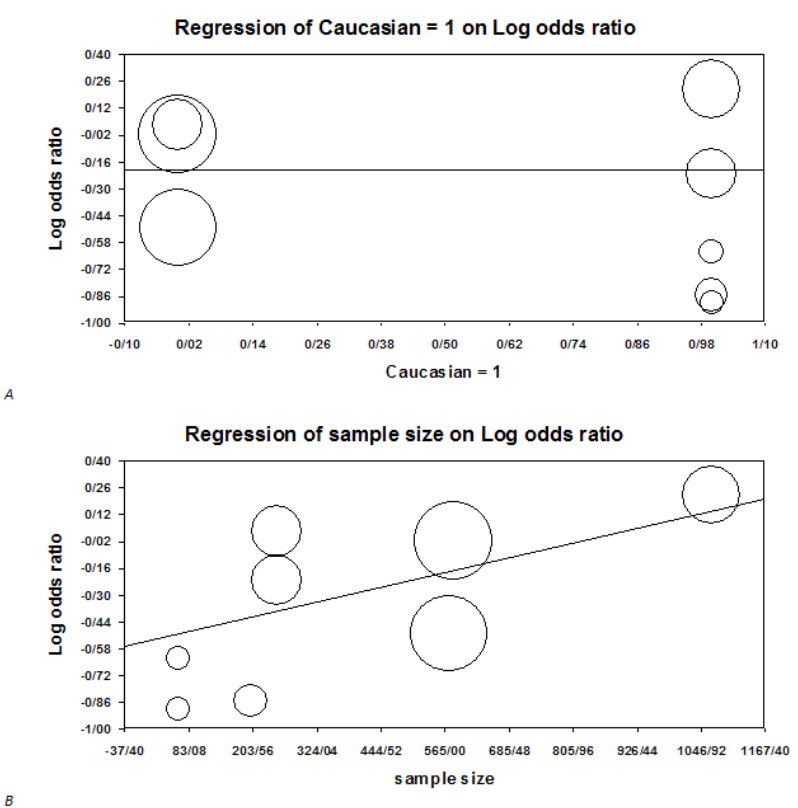

Figure 11. (A) Meta-regression of $D /$ vs $D D+/ /$ for ethnicities of the studied populations. B) Meta-regression of $D /$ vs $D D+/ /$ for sample size of the studied populations ( ${ }^{*}$ Slope $P=0.020$ ) 
a very low dose of captopril in the PCOS patients having $D D$ genotype in future as clinical trials. This dose should be lower than usual because of the risk of hyperkalemia. Of course captopril will be just a scientific model for ACE inhibition, not a secondary usage for this medication. Further investigation on ovary ACE system is needed.

\section{Ethical Issues}

Not applicable

\section{Conflict of Interests}

Authors declare that they have no conflict of interest.

\section{Financial Support}

None.

\section{Acknowledgments}

Hereby, we appreciate our colleague Dr. Beigi Boroujeni, a respected member of Department of Anatomical Sciences, Lorestan University of Medical Sciences. Also, we appreciate Mr. Afshin Hasanvand and Dr. Amin Hasanvand for their pharmacological consultant.

\section{References}

1. Ahmadi P, Hoseini R, Rahimi-Moghaddam P, Yasin Ahmadi SA. Sensitivity or resistance to steroid therapy in children with idiopathic nephrotic syndrome is not associated with polymorphism of angiotensin converting enzyme (ACE). J App Pharm Sci. 2016;6(12):206-208. doi:10.7324/JAPS.2016.601231.

2. Ahmadi P, Ahmadvand H, Ahmadi SAY, Hoseini R, Rahimi-Moghaddam P. A narrative review on nephrotic syndrome emphasizing its correlation with polymorphism of angiotensin converting enzyme and renin-angiotensin system. Crescent J Med Biol Sci. 2017;4(2):41-46.

3. Yoshimura Y, Koyama N, Karube M, et al. Gonadotropin stimulates ovarian renin-angiotensin system in the rabbit. J Clin Invest 1994;93(1):180-7. doi:10.1172/JCI116943.

4. Vrtačnik-Bokal E, Klun IV, Verdenik I. Follicular oestradiol and VEGF after GnRH antagonists or GnRH agonists in women with PCOS. Reprod Biomed Online. 2009;18(1):2128. doi:10.1016/S1472-6483(10)60420-8.

5. Faghfoori Z, Goodarzi R, Shadnoush M, Pourghasem Gargari B, Fazelian S. Nutritional management in women with polycystic ovary syndrome. J Med Council Khorramabad. 2016;1:47-60.

6. Jalilian A, Kiani F, Sayehmiri F, Sayehmiri K, Khodaee Z, Akbari M. Prevalence of polycystic ovary syndrome and its associated complications in Iranian women: a metaanalysis. Iran J Reprod Med. 2015;13(10):591-604.

7. Ajam KA, Farzadi L, Nouri M, Sadagheani MM. The effect of nitric oxide with minimal stimulation on patients with polycystic ovarian syndrome. Int J Womens Health Reprod Sci. 2014;2(3):119-130. doi:10.15296/ijwhr.2014.19.

8. Aslan G, Aslan RC, Sade LE, et al. Evaluation of polycystic ovary syndrome patients with strain echocardiography. Int J Womens Health Reprod Sci. 2014;3(1):25-30. doi:10.15296/ ijwhr.2015.05.

9. Amini L, Tehranian N, Movahedin M, Ramezani Tehrani F, Soltanghoraee H. Polycystic ovary morphology (PCOM) in estradiol valerate treated mouse model. Int J Womens
Health Reprod Sci. 2016;4(1):13-17. doi:10.15296/ ijwhr.2016.04.

10. Diamanti-Kandarakis E, Economou F, Palimeri S, Christakou C. Metformin in polycystic ovary syndrome. Ann N Y Acad Sci. 2010;1205:192-198. doi:10.1111/j.17496632.2010.05679.x.

11. Jia H, Wang B, Yu L, Jiang Z. Association of angiotensinconverting enzyme gene insertion/deletion polymorphism with polycystic ovary syndrome: a meta-analysis. J Renin Angiotensin Aldosterone Syst. 2013;14(3):255-262. doi: $10.1177 / 1470320312452768$

12. Duval S, Tweedie R. Trim and fill: a simple funnel-plotbased method of testing and adjusting for publication bias in meta-analysis. Biometrics. 2000;56(2):455-463. doi:10.1111/j.0006-341X.2000.00455.x.

13. Sun J, Fan $\mathrm{H}$, Che $\mathrm{Y}$, et al. Association between ACE gene I/D polymorphisms and hyperandrogenism in women with polycystic ovary syndrome (PCOS) and controls. BMC Med Genet. 2009;10:64. doi:10.1186/1471-2350-10-64.

14. Celik O, Yesilada E, Hascalik S, et al. Angiotensin-converting enzyme gene polymorphism and risk of insulin resistance in PCOS. Reprod Biomed Online. 2010;20(4):492-498. doi:10.1016/j.rbmo.2009.12.014.

15. Karabulut A, Turgut S, Turgut G. Angiotensin converting enzyme gene insertion/deletion polymorphism in patients with polycystic ovary syndrome. Gynecol Endocrinol. 2010;26(6):393-398. doi:10.3109/09513591003632167.

16. Sun L, Lv H, Wei W, Zhang D, Guan Y. Angiotensinconverting enzyme $\mathrm{D} / \mathrm{I}$ and plasminogen activator inhibitor-1 4G/5G gene polymorphisms are associated with increased risk of spontaneous abortions in polycystic ovarian syndrome. J Endocrinol Invest. 2010;33(2):77-82. doi:10.3275/6470.

17. Bayram B, Kılıççı Ç, Önlü H, et al. Association of angiotensin converting enzyme (ACE) gene I/D polymorphism and polycystic ovary syndrome (PCOS). Gene. 2011;489(2):8688. doi:10.1016/j.gene.2011.08.012.

18. Koika V, Georgopoulos NA, Piouka A, et al. Increased frequency of the DI genotype of the angiotensin-I converting enzyme and association of the II genotype with insulin resistance in polycystic ovary syndrome. Eur J Endocrinol. 2012;166(4):695-702. doi:10.1530/EJE-11-0894.

19. Deepika M, Reddy KR, Rani VU, Balakrishna N, Latha KP, Jahan P. Do ACE I/D gene polymorphism serve as a predictive marker for age at onset in PCOS? J Assist Reprod Genet. 2013;30(1):125-130. doi:10.1007/s10815-012-99068.

20. Ożegowska K, Bogacz A, Bartkowiak-Wieczorek J, SeremakMrozikiewicz A, Pawelczyk L. Association between the angiotensin converting enzyme gene insertion/deletion polymorphism and metabolic disturbances in women with polycystic ovary syndrome. Mol Med Rep. 2016;14(6):54015407. doi:10.3892/mmr.2016.5910.

21. Panda PK, Rane R, Ravichandran R, Singh S, Panchal H. Genetics of PCOS: a systematic bioinformatics approach to unveil the proteins responsible for PCOS. Genom Data. 2016;8: 52-60. doi:10.1016/j.gdata.2016.03.008.

22. Wei LN, Li LL, Fang C, Huang R, Liang XY. Inhibitory effects of controlled ovarian stimulation on the expression of GDF9 and BMP15 in oocytes from women with PCOS. J Assist Reprod Genet. 2013;30(10):1313-1318. doi:10.1007/ s10815-013-0041-y.

23. Boroujeni MB, Boroujeni NB, Gholami M. The effect 
of progesterone treatment after ovarian induction on endometrial VEGF gene expression and its receptors in mice at pre-implatation time. Iran J Basic Med Sci. 2016;19(3):252-257.

24. Fayazi M, Beigi Boroujeni M, Salehnia M, Khansarinejad B. Ovarian stimulation by exogenous gonadotropin decreases the implantation rate and expression of mouse blastocysts integrins. Iran Biomed J. 2014;18(1):8-15. doi:10.6091/ ibj.1236.2013.

25. Cheng C, Zhang H, Zhao Y, Li R, Qiao J. Paternal history of diabetes mellitus and hypertension affects the prevalence and phenotype of PCOS. J Assist Reprod Genet. 2015;32(12):1731-9. doi:10.1007/s10815-015-0587-y.

26. Kulshreshtha B, Singh S, Arora A. Family background of Diabetes Mellitus, obesity and hypertension affects the phenotype and first symptom of patients with PCOS. Gynecol Endocrinol. 2013;29(12):1040-1044. doi:10.3109/ 09513590.2013 .829446$.

27. Jinmin L, Jianmin L, Shuqin Z, Xueqiu L, Shuyi T. The polymorphism of angiotensin-receptor gene A1166C in familial hypertension and its distribution in the Han Yellow race of China. Saudi Med J. 2013;34(10):1007-1012.

28. Vu LC, Joe E, Kirk JK. Role of statin drugs for polycystic ovary syndrome. J Fam Reprod Health. 2017;10(4):165-175.

29. Diri H, Karaburgu S, Acmaz B, et al. Comparison of spironolactone and spironolactone plus metformin in the treatment of polycystic ovary syndrome. Gynecol Endocrinol. 2016;32(1):42-45. doi:10.3109/09513590.2015 .1080679

Copyright ( 2017 The Author (s); This is an open-access article distributed under the terms of the Creative Commons Attribution License (http://creativecommons.org/licenses/by/4.0), which permits unrestricted use, distribution, and reproduction in any medium, provided the original work is properly cited. 